\title{
The Impact of Toxoplasma gondii Infection on the Vitamin D3 Levels among Women in Childbearing Age in Kirkuk Province-Iraq
}

\author{
Faten Ayoob Tayeb ${ }^{1}$, Yahay Jirjees Salman ${ }^{2 *}$, Khalidha Mohammad Ameen ${ }^{3}$ \\ ${ }^{1}$ Biology Department, M.Sc. College of Science-Kirkuk University, Kirkuk, Iraq \\ ${ }^{2}$ Department of Medical Microbiology and Immunology, Ph.D. Microbiology, Kirkuk Medical College, Kirkuk, Iraq \\ ${ }^{3}$ Department of Gynecology and Obstetric-Kirkuk Medical College, Ph.D. Gynecology and Obstetric, Kirkuk Medical College, \\ Kirkuk, Iraq \\ Email: *dr.yahyajirjeessalman@yahoo.com
}

How to cite this paper: Tayeb, F.A., Salman, Y.J. and Ameen, K.M. (2019) The Impact of Toxoplasma gondii Infection on the Vitamin D3 Levels among Women in Childbearing Age in Kirkuk Province-Iraq. Open Journal of Medical Microbiology, 9 , 151-167.

https://doi.org/10.4236/ojmm.2019.94015

Received: September 5, 2019

Accepted: November 29, 2019

Published: December 2, 2019

Copyright $\odot 2019$ by author(s) and Scientific Research Publishing Inc. This work is licensed under the Creative Commons Attribution International License (CC BY 4.0).

http://creativecommons.org/licenses/by/4.0/

\begin{abstract}
Background: Toxoplasmosis had a remarked role in disturbing pregnancy in women by abortions and congenital abnormalities outcome. Vitamin D deficiency had a role in bone fragility, osteoporosis, exposing women to fractures as well as to bone deformities in newborns. Objective: To assess the relationship between toxoplasmosis seropositivity and vitamin D abnormalities in sera of women in childbearing ages using ELISA and auto-analyzers. Methodology: A cross-sectional study was conducted by examining the sera of 153 women, who visited Azadi Teaching Hospital Gynecological and Obstetric Clinics. Their complaints involve signs of bad obstetric history (BOH) and bone disorders, versus to 46 women negative for $(\mathrm{BOH})$. Their ages ranged from 15 to 50 years. The results: The overall rate of positive toxoplasmosis was $78.43 \%$ distributed into the following rates: $22.87 \%, 49.01 \%$, and $13.07 \%$ for IgM, IgG, and IgM + IgG antibodies, $P<0.05$. Whereas the examination of sera in the control group reveals only 14 sera positive for IgG Abs, the rate was $31.12 \%$. Sera from women in the early childhood age bearing exerts high rates of $T$. gondii IgM than in sera of women aged over 46 years, $P<0.05$. Non-animal contact women sera reveal higher rates of $T$. gondii Abs than in contact women. The relationship between toxoplasmosis, urinary tract infection (UTI) and arthritis was significant. Women with previous single abortion reveal high rates of toxoplasmosis compared to multi-abortion. The impact of toxoplasmosis concerning serum vitamin D3 levels denoted as vitamin D3 deficiency in both two groups. Conclusions: The rate of toxoplasmosis among childbearing age women was high, and the relationship between toxoplasmosis and vitamin D deficiency was significant. This finding is preliminary and prone women for getting osteoporosis.
\end{abstract}




\section{Keywords}

Toxoplasmosis, Vitamin D, Congenital, Bad Obstetric History, Arthritis

\section{Introduction}

Since concerning ten years, a widespread vitamin D deficiency has grown in all Iraqi communities and in particular, in Kirkuk province among all peoples. According to available unpublished knowledge, the rate was high, particularly among women of different ages [1]. Vitamin D is a steroidal hormone whose primary function is calcium homeostasis, conserving bone, and keeps it healthy. Recently extensive researches indicate the significance of vitamin D on the far side, keeping bones healthy and robust; it has shown the connection between levels of vitamin D and cancer [2]. Deficiency or low level of vitamin D is correlative to $30 \%$ to $50 \%$ of rectal and colon cancer, breast cancer, and prostate [3].

In female reproduction, lack of vitamin D3 in an experiment done on mice showed defects in uteri development; thus, infertility shown because of incapacity to produce mature regular eggs [4]. In Saudia Arabia, a case-control study of women, disclosed that optimizing of serum vitamin $\mathrm{D}$ and calcium is crucial to stop sub-fertile women [4]. In Egypt, Sabry et al., 2013 in an exceedingly separate cohort of white and black females in North Africa regarding risk of female internal reproductive organ leiomyoma, they found a significant inverse association between the severity of fibroid among African-American females and low level of nutriment D [5].

During the fertile period, women may suffer from polycystic ovarian dysfunction (PCOS) and may associate with anovulation [6]. They recorded the frequency of low vitamin D levels among women with (PCOS) at a high ranged rate, and the rate was about $67 \%$ to $85 \%$ [7]. Vitamin D level below $20 \mathrm{ng} / \mathrm{ml}$ may exert some symptoms like Obesity, risk of cardiovascular disease, insulin resistance, menstrual irregularity, infertility, and hyper-androgenism [8] [9].

The two-primary potential importance of vitamin D involves immune modular and fetal immunologic response [10]. The associations between $25(\mathrm{OH})$ vitamin $\mathrm{D}$ and the first trimester of miscarriages are high, moderate within the second trimester. Contrary to the third trimester, this association becomes weak, suggesting vitamin $\mathrm{D}$ as a modifiable risk issue for miscarriage [11].

The impacts of the parasitic infections attributed to some factors, such as nutrition, immune status, amount of ingested parasite, parasite virulence, and location inside of the host. Tissue parasites had severe influences on the host, in particular, human beings; an example of that is a coccidian protozoan parasite "Toxoplasma gondii." This parasite is cosmopolitan, that infect a cat, the final host, whereas most of the mammals are infected in nature through contamination by the different stages of this parasite [12]. Morphologically the stages involve two kinds of trophozoites, namely, tachyzoites (actively motile) and bra- 
dyzoites (sluggishly motile), tissue cysts (in the intermediate host mostly) and the oocysts (Immature when discharges and mature after 3 to 7 days in the environment) [13]. Transmission is by different modes such as water, raw milk, un-properly cooked meat, unwashed vegetables, blood donations, through medical tools, and mainly by Oocysts, which contains two sporocysts, each one contains four sporozoites [14] [15].

Clinically, the disease is self-limiting among immunocompetent called acquired toxoplasmosis, while in massive infection, the picture of the disease can involve: acute, sub-acute, and chronic stages [16]. The most dominant features are mimicking to febrile diseases like fever, malaise, fatigue, and sings of lymphadenopathy. The picture becomes more severe and life-threatening in immune-compromised and depleting diseases individuals [17]. The ability of the trophozoites contact fetus through the placenta, enable it to reach the fetus and cause the second picture "congenital toxoplasmosis" in women during gestational periods [18].

Compliance in women involves habitual, missed, or spontaneous abortions. Abortions can occur high in the first trimester and slightly at a low rate in the second trimester, while acquiescing the infection in the third trimester can give rises to definitive congenital abnormalities. The events of pathogenesis included: hydrocephalus, microcephaly, Chorio-retinitis, meningoencephalitis, potentially leading to death (stillbirth) [19]. Infants for infected mothers mainly when she acquires the infection in the third trimester, mostly accompanied by chorioretinitis, blindness, deafness, mental retardation, difficulties in motion, and epilepsy [20]. In males and unmarried girls, their sera reveal specific sufficient antibodies able to prevent subsequent infection with the same parasite (sterile immunity). In contrast, married women, $s$ immune response most often associated with seroconversion due to reactivation of latent or chronic infections [21]. Furthermore, T-helper 1 and 2 lymphocytes have had an experimental role in eliminating the infection inter and extra-cellularly. Serology is the method of choice for the diagnosis of Toxoplasma gondii like ELISA, (Direct fluorescent assay (DFA), DAT (Direct agglutination test (DAT)), Rapid Lateral Immuno-chromatography assay (RILICA), and different types of PCR technology [22].

According to available data, in Iraq, information or researches regarding disorder of vitamin D 3 disorders, calcium, parathyroid hormone, inorganic phosphorous, and its relation to women toxoplasmosis is absent, so the current study was aimed at to achieve that in Kirkuk city using some serological and biochemical tests.

\section{Materials and Methods}

Period and place: The current study was carried on from 1th of December 2018 to 30 June 2019 in Azadi teaching Hospital and laboratories of the KirkukMedical College.

Study design and subjects: A cross-sectional was performed on two groups 
of women, first group women with Bad obstetric History (BOH) and signs of bone disorders. The second group of women has no $\mathrm{BOH}$, their ages ranged from 15 years to over 46 years.

Exclusion criteria: Sera of women revealed positive for other etiological agents of $\mathrm{BOH}$, like Cytomegalovirus, Rubella, and human Herpes simplex viruses were excluded and not enrolled in the study.

Ethical approval: The permission for carrying on the study, according to the roles of the scientific committee in the Kirkuk Health Directorate, was taken according to the administrative issue 4731 on 13 February 2019. For each woman, a commitment was taken informal questionnaire involve, the signature of the patient to participate in the study and all required information such as name, age, occupation, blood group, and others.

\section{Sample collections and serum separation:}

$5 \mathrm{ml}$ of venous blood was drawn from each woman in both groups using sterile technique. The first tube contains $0.4 \mathrm{ml}$ of sodium citrate for erythro-sedimentation rate (ESR). The second tube contains Ethylene diamine tetra-acetic acid (EDTA) used for complete blood count (CBC) by adding about one $\mathrm{ml}$ of the blood. The rest blood sample was discharged gently into the third tube, which contains jell-activator that facilitates blood clotting and obtaining clear sera [23]. Tube 1 and two were inverted several times to a sure no clots and used at once to avoid hemolysis, in case of delay predicting the specimens kept in the refrigerator for no longer than 24 hours. The third tube, after 10 minutes, centrifuged for 5 minutes using the speed 3000 RPM. Then bright, non-hemolysis, no lipemia nor jaundice serum was transferred into another sterile plan tube and kept at $-20^{\circ} \mathrm{C}$ till to use [24].

Laboratory tests: Involve detection of $T$. gondii IgM and IgG Abs using ELISA kits and sandwich technique, Vitamin D3 uses a combination of ELISA-fluorescent technique in Mini-Vidas machine, Calcium, inorganic phosphate using a spectrophotometric method and parathyroid hormone using the sandwich ELISA kit. All the tests have been determined according to the leaflet of each kit.

Detection of anti-Toxoplasma gondii using an ELISA IgM kit.

This ELISA kit was brought by Biozek Company the Netherlands from Bio-Activia Company in German and send to our destination.

\section{Principle of ELISA kit for $T$. gondii:}

Immuno-globulins and subsequent identification of the Toxoplasma IgM assay based on capturing the ELISA technique. Which are specifically made to bind an antigen conjugated to peroxidase. The capture technique is performed by adhesion of solid-phase antigen on micro-plate to monoclonal antibodies. The antigen is a purified protein inactivated Toxoplasma gondii antigen.

Detection of anti-Toxoplasma gondii using an ELISA IgG kit. This ELISA kit was brought by Biozek Company-the Netherlands from Bio-Activia Company in German and send to our destination. The content of the kit was the same for 
IgM except, solid face antigen in the ELISA strips, HRP-conjugate. The test processing and results were the same as those used for IgM. These procedures were performed according to the manufactured company and according to that done by [25].

\section{Vitamin D determination:}

The VIDAS ${ }^{\otimes} 25-\mathrm{OH}$ Vitamin D total assay design based on a 2-step competitive immune-assay. The kit purchased from biomerurix company-France. The Mini-Vidas machine is an automated machine that determines different laboratory tests, particularly hormonal, immunological tests using a mixed method of ELISA and fluorescent. The purpose of the kit employee was to evaluate the technical and clinical performance of the VIDAS ${ }^{\otimes} 25-\mathrm{OH}$ Vitamin D total assay and to compare the result with liquid chromatography Mass Spectrometry/ Mass Spectrometry (LC-MS/MS) AND a commercially available vitamin D immune-assay. Briefly, the procedure included two following main steps: First step: Serum or plasma $25(\mathrm{OH}) \mathrm{D}$ dissociated from its protein carrier (DBP) then added to alkaline phosphatase (ALP) conjugated vitamin D-Specific antibody Second step: Unbound ALP antibody exposed to vitamin D analog coated solid-phase receptor. Solid-phase washed, and substrate reagent is added to initiate the fluorescent reaction. An inverse relationship exists between the amount of $25(\mathrm{OH}) \mathrm{D}$ in the sample and the number of relative fluorescence units detected in the serum. The result of each serum obtained after 45 minutes, which involves deficiency below $20 \mathrm{ng} / \mathrm{ml}$, insufficient from 20 to $30 \mathrm{ng} / \mathrm{ml}$, sufficient from 30 to $70 \mathrm{ng} / \mathrm{ml}$ and above $70 \mathrm{ng} / 100 \mathrm{ml}$ consider as vitamin D toxicity.

Parathyroid hormone assessment: The specific kit is an ELISA-Biotech Spain

Principle: The Intact PTH immune-assay is an adapted two-site sandwich ELISA. In the assay, standards and patient samples simultaneously incubated with the enzyme-labeled detection antibody and biotin coupled capture antibody in a streptavid in-coated micro-plate well. At the end of the assay incubation, the micro-well is washed to remove unbound components and the enzyme bound to the solid phase, incubated with the substrate tetra-methyl-benzidine (TMB). An acidic stopping solution is then added to stop the reaction and converts the color to yellow. The intensity of the yellow color is directly proportional to the concentration of intact PTH in the sample. Standards are used to generate a dose-response curve of absorbance unit vs. concentration. Concentrations of intact PTH present in the controls and patient samples are determined directly from the standard calibration curve. The typical range is from 10 to $90 \mathrm{pg} / \mathrm{ml}$.

\section{Serum inorganic phosphate determination.}

The U.V. spectrophotometry Bi-Labo-France kit was used for the determination of serum inorganic phosphate.

Serum calcium assessment: was done according to the instruction of Randox kit-UK, the manufactured company. 
Statistical analysis: All obtained data were unified and arranged in specific tables using Microsoft excel file. Differences in the parameters in both study and control groups were checked by using the manual statistical equation like chi-square and $\mathrm{t}$-student test for exerting variances and significances at the levels of $P<0.05$ and $P<0.01$.

\section{Results}

The overall rate of positive toxoplasmosis was $78.43 \%$ distributed into the following rates: $22.87 \%, 49.01 \%$, and $13.07 \%$ for IgM, IgG, and IgM + IgG antibodies, $\mathrm{p}<0.05$. Whereas the examination of sera in control group reveals only 14 sera positive for IgG Abs, the rate was $31.12 \%$. The variance in the rates of IgG Absin both groups was significant, via which the following rates were recorded $49.01 \%$ in test groups versus to $31.12 \%$ in the control group, Table 1 .

Toxoplasma gondii antibodies frequencies concerning women ages shown in Table 2, through which, sera from women in early child age bearing exert high rates of $T$. gondii IgM than in sera of women aged over than 46 years, $\mathrm{P}<0.05$. The following IgM rates were recorded $21.21 \%, 24.59 \%$, and $25 \%$ in the first three groups versus to $18.51 \%$ in sera of women over 46 years, respectively. Contrary to IgG Abs rate, $59.25 \%$ revealed in sera of women aging over 46 years

Table 1. Toxoplasma gondii antibodies positive and negative percentages in both test and control groups.

\begin{tabular}{ccccccc}
\hline Toxoplasma Antibodies & \multicolumn{2}{c}{ IgM } & \multicolumn{2}{c}{ IgG } & \multicolumn{2}{c}{ IgM + IgG } \\
\hline Number and percentages & No. & $\%$ & No. & $\%$ & No. & $\%$ \\
\hline Positive (test) & 22.87 & $35 \mathrm{a}$ & 75 & $49.01 \mathrm{~b}$ & 20 & $13.07^{* *}$ \\
Negative (test) & 118 & 77.13 & 78 & 50.98 & 133 & $86.93^{*}$ \\
Total (test) & 153 & 100 & 153 & 100 & 153 & 100 \\
Control + ve & 0.0 & $0.0 \mathrm{~A}$ & 14 & $31.12 \mathrm{~B}$ & 0.0 & 0.0 \\
Control -ve & 0.0 & 0.0 & 0.0 & 0.0 & 0.0 & 0.0 \\
Total control & 0.0 & 0.0 & 14 & 31.12 & 0.0 & 0.0 \\
\hline
\end{tabular}

${ }^{\star} 19$ Sera reveal positivity for IgM + IgG ABS. a, A, b and B, $P<0.05$. ${ }^{\star \star}$ Total sera positive for toxoplasmosis $(\operatorname{IgM}, \mathrm{IgG}$, and $\operatorname{IgM}+\operatorname{IgG})=120(78.43 \%)$.

Table 2. Frequencies of Toxoplasma gondii antibodies concerning women ages.

\begin{tabular}{ccccccccc}
\hline Age group/years & $\begin{array}{c}\text { No. } \\
\text { exam }\end{array}$ & $\%$ & $\begin{array}{c}\text { No. Toxo } \\
\text { IgM + ve }\end{array}$ & $\begin{array}{c}\text { \% + ve } \\
\text { IgG + ve }\end{array}$ & $\begin{array}{c}\text { No Toxo } \\
\text { IgM + IgG + ve }\end{array}$ & $\begin{array}{c}\text { No Toxo } \\
\text { IgM }\end{array}$ \\
\hline $15-25$ & 33 & 21.57 & 7 & 21.21 & 16 & 48.48 & 5 & $15.15 \mathrm{c}$ \\
$26-35 \mathrm{a}$ & 61 & 39.86 & 15 & 24.59 & 31 & 50.81 & 8 & 13.11 \\
$36-45$ & 32 & 20.91 & 8 & $25.00 \mathrm{~b}$ & 12 & 37.5 & 4 & 12.50 \\
Over 46 & 27 & 17.64 & 5 & 18.51 & 16 & 59.25 & 2 & 7.40 \\
Total & 153 & 100 & 35 & 22.87 & 75 & 49.01 & 20 & 13.07 \\
\hline
\end{tabular}

a, b and c Significant $(P<0.05)$. 
higher than in sera of younger women. Moreover, the sub-acute case as the sera was positive for both antibodies, IgM and IgG were highly recorded among in age group from 15 to 25 years, the rate was $15.15 \%$ compared to $7.40 \%$ in two sera of women arguing over than 46 years, $\mathrm{P}<0.05$. In general the all rate of $T$. gondii IgM Abs $22.87 \%$ versus to $49.01 \%$ for IgG Abs in the same table.

From the available data in the questionnaire form, the relationship between the occurrence of toxoplasmosis and women contact with animals, particularly with domesticated cats, chickens, Table 3 was clarifying that, the mean value of T. gondii IgM $0.96 \mathrm{IU} / \mathrm{ml}$ in the test group was higher than $0.525 \mathrm{IU} / \mathrm{ml}$ in the control group. The same finding was seen regarding IgG Abs, which was positive $1.21 \mathrm{IU} / \mathrm{ml}$ in the test group compared to $0.825 \mathrm{IU} / \mathrm{ml}$ (negative) in the control group, $P<0.05$. Sera from women in early child age bearing exerts high rates of T. gondii IgM than in sera of women aged over 46 years, $P<0.05$.

To assess the impact of Toxoplasmosis on women, abortion, Table 4 showed high positivity $63.64 \%$ in sera of women who had a single abortion, followed by

Table 3. Relationship between types of Toxoplasma gondii antibodies and women contact with the animal and not contact.

\begin{tabular}{|c|c|c|c|c|}
\hline \multirow{2}{*}{$\begin{array}{c}\text { Types of contact } \\
\text { Control group }\end{array}$} & \multicolumn{2}{|c|}{ Positive } & \multirow{2}{*}{$\begin{array}{c}\text { Toxo IgM } \\
\text { Mean } \pm \text { S.E. }\end{array}$} & \multirow{2}{*}{$\begin{array}{c}\text { Toxo IgG } \\
\text { Mean } \pm \text { S.E. }\end{array}$} \\
\hline & No. & $\%$ & & \\
\hline Contact & 14 & 31.12 & $0.54 \pm 0.02$ & $0.81 \pm 0.01$ \\
\hline Not contact & 31 & 68.88 & $0.51 \pm 0.01$ & $0.84 \pm 0.2$ \\
\hline Total & 45 & 100 & $0.525 \pm 0.13 a$ & $0.825 \pm 0.12$ \\
\hline \multicolumn{5}{|l|}{ Test group a } \\
\hline Contact & 59 & 38.56 & $0.76 \pm 0.02$ & $1.11 \pm 0.22$ \\
\hline Not contact & 94 & 61.44 & $1.17 \pm 0.12$ & $1.32 \pm 0.20$ \\
\hline Total & 153 & 100 & $0.965 \pm 0.07 \mathrm{~A}$ & $1.21 \pm 0.21$ \\
\hline \multicolumn{5}{|l|}{ All total } \\
\hline Contact & 73 & 47.71 & $0.65 \pm 0.1 b$ & $0.96 \pm 0.21 \mathrm{~B}$ \\
\hline Not contact & 125 & 41.11 & $0.84 \pm 0.12$ & $1.07 \pm 0.16$ \\
\hline
\end{tabular}

$\mathrm{a}$ and $\mathrm{b}=$ significant $(p<0.05)$.

Table 4. Frequencies of Toxoplasma gondii antibodies among women regarding the number of abortions and congenital abnormalities.

\begin{tabular}{cccc}
\hline \multicolumn{2}{c}{ Toxoplasma gondii antibodies } & IgM & IgG \\
\hline $\begin{array}{c}\text { Adverse outcomes of } \\
\text { Toxoplasmosis }\end{array}$ & $\begin{array}{c}\text { Positive } \\
\text { No.\% }\end{array}$ & $\begin{array}{c}\text { IgM level } \\
\text { Mean } \pm \text { S.E }\end{array}$ & $\begin{array}{c}\text { IgG level a } \\
\text { Mean } \pm \text { S.E }\end{array}$ \\
\hline $\begin{array}{c}\text { Single abortion b } \\
\text { Multiple abortions }\end{array}$ & 9963.64 & $0.72 \pm 0.01$ & $1.025 \pm 0.13$ \\
Stillbirth & 6742.94 & $0.83 \pm 0.02 \mathrm{c}$ & $1.00 \pm 0.12$ \\
Total & 3321.15 & $0.63 \pm 0.01$ & $1.00 \pm 0.14$ \\
\hline
\end{tabular}

Total Number examined $=156 . \mathrm{a}, \mathrm{b}$, and $\mathrm{c}, P<0.05$. 
$42.94 \%$ women with multiple abortions whereas women with stillbirth delivery contributed $21.15 \%, P<0.05$. The rate of women abortions in the current study was $42.30 \%$. T. gondii IgG Abs mean equal to $1.008 \mathrm{IU} / \mathrm{ml}$ versus to $0.072 \mathrm{IU} / \mathrm{ml}$ for IgM Abs. Furthermore, among women with multiple abortions, the mean IgM Abs level showed $0.83 \mathrm{IU} / \mathrm{ml}$ higher rate than in the case of women with single abortion and stillbirth, $P<0.05$.

To determine signs and symptoms associated with women's toxoplasmosis, the more dominant one was a urinary tract infection (UTI), the rate was $43.79 \%$, followed by $29.41 \%, 20.92 \%$, and $5.88 \%$ among women with arthritis, hypertension and diabetes mellitus respectively, $P<0.05$. Statistically, the variance in the rates of toxoplasmosis according to the existence of signs and symptoms was not significant, $P>0.05$. On the other hand, the mean levels of $T$. gondii antibodies were $1.29 \mathrm{IU} / \mathrm{ml}$ and $1.53 \mathrm{IU} / \mathrm{ml}$ for $\mathrm{IgM}$ and $\mathrm{IgG}$ Abs, respectively. Different high means of both Abs were visible in consider to symptoms; $1.41 \mathrm{IU} / \mathrm{ml} \mathrm{IgM}$ was highest recorded among women with arthritis, while $2.29 \mathrm{IU} / \mathrm{ml}$ mean level was recorded among women with hypertension Table 5.

Some bone markers levels collectively with $T$. gondii mean Abs was summarized in Table 6, through which; IgG means equal to $1.06 \mathrm{IU} / \mathrm{ml}$ (positive) in the test group versus to $0.80 \mathrm{IU} / \mathrm{ml}$ in the control group, whereas IgM Abs both were at negative levels, although IgM in the test group was slightly higher at 0.71 $\mathrm{IU} / \mathrm{ml}$ than $0.505 \mathrm{IU} / \mathrm{ml}$ in the control group.

Regarding the four bone biomarkers, all their means were within low levels in the test group compared to normal levels in the control group, $P<0.05$ Hypophosphatemia $2.60 \mathrm{mg} / 100 \mathrm{ml}$ as mean was recorded in sera of women in the test group versus to $3.87 \mathrm{mg} / 100$ mean level in the control group, $P<0.05$.

Table 5. Frequencies of some signs and symptoms among women with bone disorders in test and control groups.

\begin{tabular}{ccccccc}
\hline & \multicolumn{2}{c}{ Examined } & \multicolumn{2}{c}{ Positive } & Toxo IgM & Toxo IgG \\
\cline { 2 - 7 } Signs and symptoms & No. & $\%$ & No. & $\%$ & Mean \pm S.E & Mean \pm S.E \\
\hline UTI *(test) & 67 & 43.79 & 15 & 22.38 & $1.3 \pm 0.01$ & $1.43 \pm 0.02$ \\
UTI control & 14 & 31.11 & 8 & 15.38 & 0.00 & $1.06 \pm 0.012$ \\
Arthritis (test) & 45 & 29.41 & 10 & 22.22 & $1.41 \pm 0.02$ & $1.34 \pm 0.04$ \\
Arthritis (control) & 16 & 35.55 & 4 & 25.00 & 0.00 & $1.18 \pm 0.11$ \\
Hypertension (test) & 32 & 20.92 & 8 & 25.00 & $1.36 \pm 0.02$ & $2.29 \pm 0.06$ \\
Hypertension (control) & 13 & 28.88 & 3 & 23.07 & 0.00 & $0.94 \pm 0.04$ \\
D.M ${ }^{* *}$ (test) & 9 & 5.88 & 2 & 22.22 & $1.12 \pm 0.03$ & $1.09 \pm 0.01$ \\
D.M (control) & 2 & 4.44 & 1 & 50.00 & 0.00 & $0.92 \pm 0.01$ \\
Total (test) & 153 & 100 & 35 & 22.87 & $1.29 \pm 0.01$ & $1.53 \pm 0.03$ \\
Total (control) & 45 & 100 & 16 & 35.55 & 0.00 & $1.02 \pm 0.02$ \\
\hline
\end{tabular}

${ }^{*} \mathrm{UTI}=$ Urinary tract infection. ${ }^{*}$ D.M $=$ Diabetes Mellitus. 
Table 6. Bone biomarkers in both study and control groups during toxoplasmosis compare to IgM and IgG antibodies in both groups.

\begin{tabular}{ccccc}
\hline Groups & \multicolumn{2}{c}{ Study group } & \multicolumn{2}{c}{ Control group } \\
\hline Types of Toxoplasma antibodies & IgM & IgG & IgM & IgG \\
\hline Antibodies levels & Mean \pm S.E & Mean \pm S.E & Mean \pm S.E & Mean \pm S.E \\
Antibodies levels & $0.715 \pm 0.04$ & $1.06 \pm 0.08 \mathrm{a}$ & $0.505 \pm 0.02$ & $0.805 \pm 0.04$ \\
Biomarkers & & & & \\
Inorganic phosphate & $2.60 \pm 0.06$ & $3.88 \pm 0.25 \mathrm{~b}$ \\
Calcium & $8.20 \pm 0.05$ & $8.83 \pm 0.15$ \\
Vitamin D3 & $16.59 \pm 1.13 \mathrm{c}$ & $13.90 \pm 0.65$ \\
PTH & $14.96 \pm 2.35 \mathrm{~d}$ & $25.76 \pm 2.14$ \\
\hline
\end{tabular}

A, b, c, d significant $P<0.05, \mathrm{PTH}=$ parathyroid hormone.

Although the mean value of vitamin D3 $13.90 \mathrm{ng} / \mathrm{ml}$ in the sera of women in the control group was low compared to $16.59 \mathrm{ng} / \mathrm{ml}$ in the test group, in both groups, the condition is a deficiency of vitamin D3. The difference in the values of vitamin D3 in both groups was not significant. Significant differences were seen in the levels of serum parathyroid hormone (PTH) between the test group, which showed hypoparathyroidism, and the mean was $14.96 \mathrm{pg} / \mathrm{ml}$ versus to $24.01 \mathrm{pg} / \mathrm{ml}$ in sera of women in the control group, $P<0.05$.

The frequency of T.gondii Abs, according to vitamin D3 abnormalities, was tabulated in Table 7, via which Toxo-IgM Abs was highly observed 18.43\% among sera deficient to vitamin D3 followed by $4.60 \%$ and $1.31 \%$ for insufficiency and toxicity, $P<0.05$. The same finding detected regarding Toxo-IgG Abs, the following rates $31.57 \%, 9.21 \%$, and $1.97 \%$ for a vitamin Ddeficiency, insufficiency, and toxicity were recorded respectively, P,0.05. In general, the total Toxo-Abs was $62.5 \%$ distributed in 95 sera, and this rate involves $24.34 \%$ for Toxo-IgM Abs versus to $38.15 \%$ for Toxo-IgG Abs.

The impact of toxoplasmosis concerning serum vitamin D3 levels denoted as vitamin D3 deficiency. It recorded in sera of 117 women positive for toxoplasmosis; the rate was $76.97 \%$ of all total of vitamin D3 abnormality $93.42 \%$ compared to $6.58 \%$ of women their sera exert an average vitminD3 level. Also, insufficiency recorded at a rate of $14.47 \%$. While toxicity was shown in 3 sera, the rate was $1.97 \%, P<0.05$.

The relationship between vitamin D3 deficiency, toxoplasmosis, and women's age was significant; within which women were aging from 15 to 25 years, their sera reveal high rates of deficiency $98.46 \%$ compared to other age groups. While vitamin D3 insufficiency highest recorded among women aging from 26 to 35 years, $P<0.05$ Table 8 .

\section{Discussion}

The Provinces in the north and west of Iraq suffer from the destruction of infrastructure during 2014 and after with continuous instability. In addition to 
Table 7. Distribution of Toxoplasma gondii antibodies, both IgM and IgG, concerning vitamin D-3 abnormalities.

\begin{tabular}{cccccccccc}
\hline & \multicolumn{4}{c}{ Abnormal Vitamin D-3 levels } & \multicolumn{2}{c}{ Total } \\
\cline { 2 - 7 } Types of & \multicolumn{3}{c}{$\begin{array}{c}\text { Deficiency } \\
\text { Toxoplasma gondii antibodies }\end{array}$} & \multicolumn{2}{c}{ Insufficiency } & \multicolumn{2}{c}{ Toxicity } & \multirow{2}{*}{ No. } & $\%$ \\
\cline { 2 - 8 } & No & $\%$ & No & $\%$ & No. & $\%$ & & \\
\hline Toxo IgM + ve & 28 & 18.43 & 7 & 4.60 & 2 & 1.31 & 37 & 24.34 \\
Toxo IgG + ve & 48 & $31.57 \mathrm{~b}$ & 7 & 4.60 & 3 & 1.97 & 58 & 38.15 \\
Total & 76 & 50 & 14 & 9.21 & 5 & 3.28 & 95 & $62.5 \mathrm{a}$ \\
\hline
\end{tabular}

Deficiency (below 20), insufficiency (20 to 30 ), Toxicity is (70 to 100) and Normal (30 to 70). a and b; $P<$ 0.05 .

Table 8. The relationship between women's toxoplasmosis according to ages.

\begin{tabular}{|c|c|c|c|c|c|c|c|c|c|c|}
\hline \multirow{3}{*}{$\begin{array}{c}\text { Age } \\
\text { groups/Years }\end{array}$} & \multicolumn{6}{|c|}{ Abnormal Vitamin D-3 levels } & \multicolumn{2}{|c|}{ Total } & \multicolumn{2}{|c|}{$\begin{array}{c}\text { Normal } \\
\text { Vitamin D-3 }\end{array}$} \\
\hline & \multicolumn{2}{|c|}{ Deficiency } & \multicolumn{2}{|c|}{ Insufficiency } & \multicolumn{2}{|c|}{ Toxicity } & \multirow{2}{*}{ No. } & \multirow{2}{*}{$\%$} & \multirow{2}{*}{ No. } & \multirow{2}{*}{$\%$} \\
\hline & No & $\%$ & No & $\%$ & No. & $\%$ & & & & \\
\hline 15 to 25 & 30 & 98.46 & 0.00 & 0.00 & 0.00 & 0.00 & 30 & 98.46 & 2 & 1.54 \\
\hline 26 to 35 & 39 & 62.90 & 19 & 30.64 & 1 & 1.61 & 60 & 96.78 & 2 & 3.22 \\
\hline 36 to 45 & 27 & 85.37 & 2 & 6.25 & 1 & 3.12 & 30 & 93.75 & 2 & 6.25 \\
\hline 46 above & 21 & 77.78 & 1 & 3.70 & 1 & 3.70 & 23 & 85.18 & 4 & 14.82 \\
\hline Total & 117 & 76.97 & 22 & 14.47 & 3 & 1.97 & 142 & 93.42 & 10 & 6.58 \\
\hline
\end{tabular}

Deficiency (below 20), insufficiency (20 to 30 ), Toxicity is (70 to 100) and Normal (30 to 70).

uncontrolled construction of houses with inadequate designs, continuous electricity interruption, shortages in the water supply with weak governmental monitoring water. The competition of commercial companies for bringing bad quality drugs had a role in recording several infectious agents with high rates in Iraq particularly, Toxoplasmosis [25], Giardiasis [26], Cyclospora cayetanensis [27], Blastocystis hominis [28].

So, the all rate of seropositive toxoplasmosis $78.43 \%$ among women with child, conceiving age was high for these reasons. This rate was due to the sensitivity of the ELISA test compared to the other serological method used by other authors in this regard for the diagnosis of toxoplasmosis in the same province. The overall rate of toxoplasmosis in the present study did not agree with that recorded in the same province by [29] [30] [31], whom they record the following rates: $33.6 \%, 35.6 \%$, and $31.15 \%$. Also, it has disagreed with those recorded [32] [33] [34], whom they record $92.1 \%, 48.9 \%$ and $38.56 \%$ of toxoplasmosis in the same province, respectively. These characteristic findings of $T$. gondii seropositivity were higher than those recorded by other studies, including Egypt, by [35] [36]. In Turkey by [37]. In Malaysia, India, Saudi Arabia, Mali, and northeast Thailand [25]. Also, it was deficient when it was compared with $83.6 \%$ in Ethiopia recorded by [38]. The variability in the rates might be due to several factors, 
such as the size of samples, type of laboratory method, site of the study, and type of the patient(infected and not infected with other infectious agents) [17].

Regarding women ages and high incidence of Toxo-IgM Abs $0.96 \mathrm{IU} / \mathrm{ml}$ equivocal levels ( 0.9 to $0.99 \mathrm{IU} / \mathrm{ml})$, this finding is vital to woman health. The possibility for seroconversion after a period gives rise in IgM Abs and, subsequently, the adverse effects of toxoplasmosis like abortion and stillbirth. The importance of this finding is with the high occurrence of Toxo-IgM Abs in young aged women within the current study, this group of women is very fertile; the prospect for pregnancy lost is going to be high, notably within the first trimester and a few less within the second trimester. This seroconversion within the third trimester becomes a lot of harmful, as a result of congenital toxoplasmosis exerting when delivery 40. On the other hand, Toxo-IgG Abs $49.01 \%$ was high and referring that all the women in the current study got $T$. gained previously, and they have an anti-Toxoplasma antibody. However, this finding of Toxo-IgG Abs in a high level demands assurance like watching of rising titer to exclude seroconversion and to assure protection. Also, these high rates in the levels of both Toxo-Abs reflect the degree of contamination with the Toxoplasma stages in Kirkuk Province. So, Health education for women of childbearing age should include information about meat-, soil-, and cat feces-related toxoplasmosis prevention. This finding, with agreement with that recorded in Najaf Province-Iraq [39] [40] [41] [42], suggests that T. gondii Abs increases with the increasing of the women age This finding is not compatible with those recorded in Iraq in Tikrit 2008 [43], Kirkuk in 2013 [44] and 2014 [45] and with that record in Nepal 2014 [45].

Stray cats dwelling houses had a significant role in spreading the oocysts of T.gondii, and unprotection during meat handling and washing vegetables can increase the rate of toxoplasmosis, particularly in women [25]. Surprise in recent, the number of indoor cats is not high. But the outcome of infection among women contact with cat, meat and vegetable high in the current study as both IgM and IgG Abs were significant, this high rate explained by some factor such as consumption of different kinds of meat from different origin (Imported meat), this meat mostly brought to Iraq without governmental inspection, wrong store due to continuous electricity interruption, poorly auditing cats by veterinarian director in addition to absence of specific drug used for treatment of toxoplasmosis in Iraq. All of these factors had a role in this relationship. This finding was agreed that recorded in Karbala-Iraq [46] [47].

Vertical transmission of $T$. gondii parasite in women mostly evokes abortion or lead to congenital abnormalities. Despite the non-significant relation between the number of abortion and Toxo-Abs frequencies, in the current study. However, a high incidence of $63.64 \%$ in sera of women with single abortion is vital because their sera reveal $0.72 \mathrm{IU} / \mathrm{ml}$ (negative titer) for IgM versus to 1.025 $\mathrm{IU} / \mathrm{ml}$ for IgG (borderline positive). In this condition, women should aware of getting the second infection, and this is due the chance of increasing, rising titer of IgM (seroconversion) in association to the partially protects as IgG Abs are at 
the level of partially protection [48]. Stillbirth is a major but often neglected public health issue [48]. The current findings indicated high stillbirth rates in Kirkuk-Iraq and identified the risk categories which were in early aged women, The development and implementation of number of maternal and child health programs at national level to date do not have a significant role in the increase or decrease of inequalities [49]. So, further studies required to evaluate the real causes of stillbirth in comparing to toxoplasmosis.

The co-existence of some signs and symptoms like UTI, arthritis, Hypertension, and DM in the current study should be taken into consideration, because of obtaining both IgM and IgG Abs with high mean compared to sera of women positive for toxoplasmosis only. The higher rate of recording of UTI might be due to contamination with genital flora, a shorter urethra, sexual activities, certain types of birth control, and the use of spermicidal agents [50]. All collectively can enhance the frequency of UTI in women. Regarding sign of arthritis, might be attributed to the effects of vitamin D deficiency in the current study, although in a previous study in the same Province done between 2014 to-2015 [51] attribute arthritis to toxoplasmosis. Moreover, most of the endo-parasitism evoke anemia, so the load on the urinary system becomes apparent, and one suggestion for getting hypertension during toxoplasmosis might be due changes in some hormones like erythropoietin and anti-diuretic hormone $(\mathrm{ADH})$ the former is responsible for anemia and the later definitively in changing urine consistency and osmolality. Additionally the possibility of adrenalin gland, which may interfere the level of cortisol hormone that increases the compliance of D.M [52].

Regarding some bone marker tests during toxoplasmosis, S.inorganic phosphorus is within normal with a significant difference with sera in the control group. Additionally, hypocalcemia, low PTH, and vitaminD3 deficiency, all referring to the picture of hypoparathyroidism. Although the etiology for this might be genetic (chromosomal) or induction by chronic diseases such as thyroid diseases, tonsillitis, but, role of Toxoplasma parasite invading cervical area lymph nodes(lymphadenopathy) had a role in interfering the function of PTH.

Furthermore, vitamin deficiency in Iraq nowadays is a mystery because the incidence of vitamin D in Iraqi communities is high. Causes to that might be less exposure to sunlight that permits good penetration for the manufacturing of sufficient amount of vitamin D; changes in the climate also have a role in this deficiency. However, the effect of $T$. gondii on the bone itself remains obscure because the bone is a rigid tissue and the morphology of osteocytes is not proper for the development of the parasite inside it. Moreover osteomalacia can result in invading the parasite to the kidneys, tubules, and small intestinal tissue through which the rate of calcium reabsorption becomes low and bone trials for compensating calcium shortage leads to osteoporosis or bone fragility mostly increases fracture occurrence and other signs and symptoms of arthritis.

High level of Toxo-IgM $18.43 \%$ association with vitamin deficiency refers to the chance of women gutting adverse effects of toxoplasmosis will be high. Addi- 
tionally, vitamin $\mathrm{D}$ deficiency might be due to a poor diet with some minerals particularly S. magnesium. So, women's supplements with oral vitamin $\mathrm{D}, \mathrm{Ca}^{2+}$, minerals may have a substantial role in preventing vitamin $\mathrm{D}$ shortage. This plane should be accompanied by finding the most effective treatment for toxoplasmosis in women rather than the use of spiramycin, which mostly used in Iraqi clinics.

\section{Conclusions}

The prevalence of $T$. gondii Abs in the sera of women was high, particularly in young aged women. Acute toxoplasmosis (High level of IgM) accompanied by vitamin D deficiency is higher among women aging from 15 to 25 years, which may have a role in women's abortion and congenital abnormalities. Seroconversion from latency is still present because the mean level of IgG Abs was within the borderline.

The relationship between toxoplasmosis and vitamin D deficiency is significant, and this finding is preliminary and prone to women for getting osteoporosis.

\section{Conflicts of Interest}

The authors have declared no potential conflicts of interest concerning the research, authorship, or publication of this article.

\section{Author's Contribution}

Tayeb, Salman, and Ameen designed the study. Ameen selects ladies and refers them to the research laboratory sampling, and a few lab test processes completed by Tayeb, data analysis, and manuscript preparation ready by Salman. Ameen and Salman suggested strategies and interpretation of finding labs. Salman reviewed the manuscript. All authors have participated in the study and concur with the submission, and future revision submitted the corresponding author.

\section{Conflicts of Interest}

The authors declare no conflicts of interest regarding the publication of this paper.

\section{References}

[1] Kimberly, Y.Z.F. and Wendy, L.S. (2011) Prevalence and Correlates of Vitamin D Deficiency in US Adults. Nutrition Research, 31, 48-54.

https://doi.org/10.1016/j.nutres.2010.12.001

[2] Michaelsson, K., Baron, J.A., Snellman, G., Gedeborg, R., Byberg, L., Sundstrom, J., Berglund, L., Arnold, J., et al. (2010) Plasma Vitamin D and Mortality in Older Men, a Community Based Prospective Cohort Study. The American Journal of Clinical Nutrition, 92, 841-848. https://doi.org/10.3945/ajcn.2010.29749

[3] Johnson, L.E. and DeLuca, H.F. (2001) Vitamin D Receptor Null Mutant Mice Fed High Levels of Calcium Are Fertile. The Journal of Nutrition, 131, 1787-1791. 
https://doi.org/10.1093/jn/131.6.1787

[4] Al-banyan, N., Johanna, N.J., Addouri, O., Al-Tannir, M. and Al-Jaroudi, D. (2016) Vitamin D Deficiency among Sub-Fertile Women: A Case-Control Study. Gynecological Endocrinology, 32, 272-275. https://doi.org/10.3109/09513590.2015.1112784

[5] Sabry, M., Halder, KS., AitAllah, AS., Roshdy, E., Rajartman, V. and Al-Hendy, A. (2013) Serum Vitamin D3 Level Inversely Correlates with Uterine Fibroid Volume in Different Ethnic Groups: A Cross-Sectional Observational Study. International Journal of Women's Health, 5, 93-100. https://doi.org/10.2147/IJWH.S38800

[6] Thomson, R.L., Spedding, S. and Buckley, J.D. (2012) Vitamin D in the Etiology and Management of Polycystic Ovary Syndrome. Clinical Endocrinology, 77, 343-350. https://doi.org/10.1111/j.1365-2265.2012.04434.x

[7] Moini, A., Shirzad, N., Ahmadzadeh, M., Hosseini, R., Hosseini, L. and Sadatmahalleh, S.J. (2015) Comparison of 25-Hydroxyvitamin D and Calcium Levels between Polycystic Ovarian Syndrome and Normal Women. International Journal of Fertility and Sterility, 9, 1-8.

[8] Luca, P., et al. (2015) The High Prevalence of Vitamin D Deficiency in Infertile Women Referring to Assisted Reproduction. Nutrients, 7, 9972-9984.

https://doi.org/10.3390/nu7125516

[9] Dressler, N., et al. (2016) BMI and Season Are Associated with Vitamin D Deficiency in Women with Impaired Fertility: A Two-Center Analysis. Archives of $G y-$ necology and Obstetrics, 293, 907-914. https://doi.org/10.1007/s00404-015-3950-4

[10] Lagishetty, V., Liu, N.Q. and Hewison, M. (2011) Vitamin D Metabolism, and Innate Immunity. Molecular and Cellular Endocrinology, 347, 97-105. https://doi.org/10.1016/j.mce.2011.04.015

[11] Hewison, M. (2012) Vitamin D, and Immune Function: Autocrine, Paracrine, or Endocrine? Scandinavian Journal of Clinical and Laboratory Investigation, 243, 92-102.

[12] Andersen, L.B., Jorgenson, J.S., Jensen, T.K., Dalgard, C., Barrington, T., et al. (2015) Vitamin D Insufficiency Is Associated with Increased Risk of First-Trimester Miscarriage in the Odense Child Cohort. The American Journal of Clinical Nutrition, 5, 633-638. https://doi.org/10.3945/ajcn.114.103655

[13] Khan, K. and Khan, W. (2018) Congenital Toxoplasmosis: An Overview of the Neurological and Ocular Manifestations. Parasitology International, 67, 715-721. https://doi.org/10.1016/j.parint.2018.07.004

[14] Robert-Gangneux, F. and Darde, M.L. (2012) Epidemiology of and Diagnostic Strategies for Toxoplasmosis. Clinical Microbiology Reviews, 25, 264-296. https://doi.org/10.1128/CMR.05013-11

[15] Jones, J.L. and Griffin, P.M. (2011) Foodborne Illness Acquired in the United States Major Pathogens. Emerging Infectious Diseases, 17, 7-15.

[16] Shafiei, B., Sohrabpour, R.M. and Kasraian, L. (2014) Seroprevalence and Molecular Diagnosis of Toxoplasma gondii Infection among Blood Donors in Southern Iran. The Journal of Infection in Developing Countries, 8, 543-547.

[17] Salman, Y.J. (2007) Serological Cross-Reaction among Some Anti Agents of Women Abortions (Toxoplasma gondii, Cytomegalovirus, and Rubella Virus), with an Incidence of Hepatitis Viruses (B and C). Tikret Journal of Pharmaceutical Sciences, 3, 8-14.

[18] Paquet, C. and Yudin, M.H. (2013) Toxoplasmosis in Pregnancy: Prevention, Screening, and Treatment. Journal of Obstetrics and Gynaecology, 35, 78-81. 
[19] Fu, C.J., Chuang, T.W., Lin, H.S., Wu, C.H., Liu, Y.C., Langinlur, M.K., et al. (2014) Toxoplasma gondii Infection: Seroprevalence and Associated Risk Factors among Primary School Children in the Capital Area of the Republic of the Marshall Islands. Japanese Journal of Infectious Diseases, 67, 405-410.

[20] Remington, R., Meier, P. and McLeod, R. (2008) Toxoplasmosis Study Group. A Longitudinal Study of New Eye Lesions in Children with Toxoplasmosis Who Were Not Treated during the First Year of Life. American Journal of Ophthalmology, 46, 375-384.

[21] Dadimoghaddam, Y., Daryani, A., Sharif, M., Ahmadpour, E. and Hossienikhah, Z. (2014) Tissue Tropism, and Parasite Burden of Toxoplasma gondii RH Strain in Experimentally Infected Mice. Asian Pacific Journal of Tropical Medicine, 7, 521-524. https://doi.org/10.1016/S1995-7645(14)60087-0

[22] AL-Rawi, K. (2009) Detection of $B 1$ Gene from the Blood of Pregnant and Abortive Women Infected with Toxoplasma gondii. Ph.D. Thesis, College of Science University of Baghdad, Baghdad, Iraq, 125.

[23] Abdulrazaq, A.A. (2017) Detection of Some Physiology and Immunological Helicobacter Pylori and Parameter Related to Some Intestinal Parasites among Patients with Gastrointestinal Disorders in Kirkuk. Ph.D. Thesis, Tikrit University, Tikrit, Iraq.

[24] Al-Jumaily, O.S. (2018) Evaluation of Calprotectin and Some Other Related Biomarkers in Gastroenteritis Patients in Kirkuk Province. Ph.D. Thesis, Tikrit University, Tikrit, Iraq.

[25] Salman, Y.J. and Mustafa, L.B. (2016) Role of Cytomegalovirus and Toxoplasma gondii in Women Abortion and Congenital Anomalies in Kirkuk City Using ELISA. Egyptian Journal of Medical Microbiology, 25, 81-89. https://doi.org/10.12816/0037024

[26] Salman, J., Al-Taee, A.A. and Abid, A.M. (2016) Role the Employee of Some Biological Stains in Detecting Giardia lamblia among Internal Iraqi Displaced Peoples in Kirkuk Province. International Journal of Current Microbiology and Applied Sciences, 5, 705-718. https://doi.org/10.20546/ijcmas.2016.503.083

[27] Salman, Y.J., Kadir, M.A. and Abdul-Allah, T.J. (2015) Prevalence of Cyclospora cayetanensis and Other Intestinal Parasites in Soil Samples Collected from Kirkuk Province. International Journal of Current Research and Academic Review, 3, 239-250.

[28] Salman, Y.J. (2015) Detection of Blastocystis hominis among Peoples in Kirkuk Province Using ELISA and Direct microscopy.Int. J. Curr. Microbiol.App. Sci., 4, 686-695.

[29] Al-Attar, S.A. (2000) Epidemiological Study of Toxoplasma gondii among Peoples and Animals in Kirkuk Province. Tikrit University, Tikrit, Iraq.

[30] Al-Jubori, A.M. (2005) Serological Study of Toxoplasmosis in Kirkuk Province. College of Technology, Baghdad, Iraq.

[31] Salman, Y.J. (2014) Echinococcus granulosus IgG Antibodies Cross-Reaction with Seropositive Toxoplasma gondii among Women with Abortion and Outcomes of Congenital Abnormalities. Tikrit University, Tikrit, Iraq.

[32] Salman, Y.J. (2014). Role of Toxoplasma gondii and Human Herpes Simplex Virus Type-2 in Omen with Abortions and Congenital Outcomes in Kirkuk City. International Journal of Current Research in Biosciences and Plant Biology, 1, 1-8.

[33] Tewfik, S.K. (2013) Some Immunological Aspects of Toxoplasmosis among Women with Abortion and Congenital Abnormalities. Tikrit University, Tikrit, Iraq. 
[34] Noori, T.K. (2013) Study the Efficacy of Laboratory Methods in Detecting Some Protozoan Parasites in Kirkuk City. University of Kirkuk, Kirkuk, Iraq.

[35] Elsheikha, H.M., Azab, M.S., Abousamra, N.K., Rahbar, M.H. and Elghannam, R.D. (2009) Seroprevalence of and Risk Factors for Toxoplasma gondii Antibodies Asymptomatic Blood Donors in Egypt. Parasitology Research, 104, 1471-1476. https://doi.org/10.1007/s00436-009-1350-Z

[36] El Deeb, H.K., Salah-Eldin, H., Khodeerc, S. and Abdul Allahd, A. (2012) Prevalence of Toxoplasma gondi Infection in Antenatal Population in Menoufia Government, Egypt. Acta Tropica, 124, 185-191. https://doi.org/10.1016/j.actatropica.2012.08.005

[37] Yazar, S., Eser, B. and Yay, M. (2006) Prevalence of Anti-Toxoplasma gondii Antibodies in Turkish Blood Donors. Ethiopian Medical Journal, 44, 257-261.

[38] Zemene, E., Yewhalaw, D., Abera, S., Belay, T., Samuel, A. and Zeynudin, A. (2012) Seroprevalence of Toxoplasma gondiiand Associated Risk Factors among Pregnant Women in Jimma Town, Southwestern Ethiopia. BMC Infectious Diseases, 10, 337. https://doi.org/10.1186/1471-2334-12-337

[39] Dabritz, H.A., et al. (2008) Risk Factors for Toxoplasma gondii Infection in Wild Rodents from Central Coastal California and a Review of T. Gondii Prevalence in Rodents. The Journal of Parasitology, 94, 675-683. https://doi.org/10.1645/GE-1342.1

[40] Mohammad, H.I., Amin, T.T., Balaha, M.H. and Moghannum, M.S. (2010) Toxoplasmosis among Pregnant Women Attending a Saudi Maternity Hospital: Seroprevalence and Possible Risk Factors. Annals of Tropical Medicine \& Parasitology, 104, 493-504. https://doi.org/10.1179/136485910X12786389891443

[41] Tabbara, K.S. and Saleh, F. (2005) Serodiagnosis of Toxoplasmosis in Bahrain. Saudi Medical Journal, 26, 1383-1387.

[42] Salih, H.A. (2010) Prevalence of Toxoplasmosis among Pregnant Women in Najaf City. Kufa Journal for Veterinary Medical Sciences, 1, 101-108.

[43] Ahmed, Z.Y. (2008) Isolation and Diagnosis of Toxoplasmosis among Women with Abortions Attending Tikrit Teaching Hospital. Tikrit University, Tikrit, Iraq.

[44] Kasim, T.N. (2013) Efficacy of Some Laboratory Methods in Detecting Protozoan Parasites in Kirkuk City. M.sc. Thesis, College of Science, Kirkuk University, Kirkuk.

[45] Acharya, D., Shrestha, A., Bogati, B., Khanal, K., Shrestha, S. and Gyawali, P. (2014) Serological Screening of Torch Agents as an Etiology of Spontaneous Abortion in Dhulikhel Hospital, Nepal. American Journal of Biomedical and Life Sciences, 2, 34-39. https://doi.org/10.11648/j.ajbls.20140202.11

[46] Aalowi, H.H., Ali, J.K. and Hamadi, K.A. (2010) Seroprevalence of Toxoplasma gondii among Pregnant Women in Baghdad Province. Journal of Kerbala University, 8, 7-11.

[47] Peyron, F., Garweg, J.G., Wallon, M., Descloux, E., Rolland, M. and Barth, J. (2011) Long-Term Impact of Treated Congenital Toxoplasmosis on Quality of Life and Visual Performance. The Pediatric Infectious Disease Journal, 30, 597-600. https://doi.org/10.1097/INF.0b013e31820bb5f3

[48] Ashish, K.C., Nelin, V., Wimmer, J., Ewald, U., Vitrakoti, R., Baral, G.N. and Målqvist, M. (2015) Risk Factors for Antepartum Stillbirth: A Case-Control Study in Nepal. BMC Pregnancy and Childbirth, 15, 146.

[49] Getahun, D., Ananth, C.V. and Kinzler, W.L. (2007) Risk Factors for Antepartum 
and Intrapartum Stillbirth: A Population-Based Study. American Journal of Obstetrics \& Gynecology, 196, 499-507. https://doi.org/10.1016/j.ajog.2006.09.017

[50] Minardia, D., d’Anzeo, G., Cantoro, D., Conti, A. and Muzzonigro, G. (2011) Urinary Tract Infections in Women: Etiology and Treatment Options. International Journal of General Medicine, 4, 333-343. https://doi.org/10.2147/IJGM.S11767

[51] Salman, Y.J. and Mohammad, K.A. (2015) Relationship between Toxoplasma gondii and Arthritis among Patients in Kirkuk City. International Journal of Current Research and Academic Review, 3, 175-187.

[52] Mitra, R., Sapolsky, R.M. and Vyas, A. (2013) Toxoplasma gondii Infection Induces Dendritic Retraction in Basolateral Amygdala Accompanied by Reduced Corticosterone Secretion. Disease Models \& Mechanisms, 6, 516-520.

https://doi.org/10.1242/dmm.009928 